\title{
Orchestrating Lean Implementation
}

\author{
Jens Ove Riis ${ }^{1}$, Hans Mikkelsen ${ }^{1}$, and Jesper Rank Andersen ${ }^{2}$ \\ 1 Center for Industrial Production, Aalborg University, Fibigerstraede 16, \\ DK-9220 Aalborg, Denmark \\ http://www.cip.aau.dk \\ 2 KnowIT ApS, Østervold 23, 2. sal, DK-8900 Randers, Denmark
}

\begin{abstract}
The notion of Lean Manufacturing is not merely confined to a set of well defined techniques, but represents a broad approach to managing a company. Working with lean entails many aspects, such as production planning and control, production engineering, product development, supply chain, and organizational issues. To become effective, many functional areas and departments must be involved. At the same time companies are embedded in a dynamic environment. The aim of the paper is to propose a comprehensive approach to better implementation of lean initiatives, based on two empirical studies. The paper will discuss how a concerted effort can be staged taking into account the interdependencies among individual improvement initiatives. The notion of orchestration will be introduced, and several means for orchestration will be presented. Critical behavioral issues for lean implementation will be discussed.
\end{abstract}

\section{Lean implementation requires a concerted organizational effort}

The notion of Lean Manufacturing is not merely confined to a set of well defined techniques, but represents a broad approach to managing an enterprise [1]. Lean draws on a number of more specific focal areas, such as Just-in-Time, Total Quality Management, Business Process Reengineering, Reduction of Waste, Flow Manufacturing. Thus, working with lean entails many aspects, such as production planning and control, production engineering, quality management, product development, supply chain, and organizational issues. To become effective, many functional areas and departments must be involved.

In many respects lean implementation seems to be no different from other management development efforts, for example introduction of computer integrated manufacturing technologies and business process reengineering. Empirical studies indicate that only a fraction of all initiatives, although technical successful, ever manage to deliver the desired competitive improvement [2]. Kaplan \& Norton [3]

Please use the following format when citing this chapter:

Riis, J.O., Mikkelsen, H. and Andersen, J.R., 2008, in IFIP International Federation for Information Processing, Volume 257, Lean Business Systems and Beyond, Tomasz Koch, ed.; (Boston: Springer), pp. 285-293. 
claims that only one out of ten companies ever succeeds in implementing strategies to the extent that intended results are achieved. This points to the importance of addressing the organizational issues related to lean implementation.

The paper will draw on the results of a study of how companies manage a portfolio of internal development initiatives [4]. It involved more than 30 companies from different industries and covered a variety of themes, including lean implementation. Also, a study of five Danish companies' work with agile portfolio management will be included [5].

The next section will place lean implementation in an organizational context. Then the notion of orchestration will be introduced to cope with internal and external dynamics. Managing interdependencies among development initiatives is key and will be discussed in a subsequent section leading to a discussion of means of forming and orchestrating a campaign and a program of internal development activities. At the end behavioral issues will be discussed.

\section{The myriad of development initiatives}

The empirical studies suggest the proposition that at any point in time in a company there are many internal development initiatives in progress competing for attention. For good reasons each functional area, e.g. sales and marketing, product development, production engineering, logistics, purchase, human relation, or ITsystems, is expected to propose activities that can improve the overall company performance. For example, production and logistics may want to improve quality, but have to rely on cooperation with product development and purchase; or the HRsection may want to launch a large-scale competence development program, but will depend on active involvement of the whole organization. In addition, top management often has its own agenda with respect to attending to the public image and shareholders' opinion which also may give rise to internal development initiatives.

Figure 1 illustrates the wide spread of internal development activities from large renewal programs involving almost all departments and functions to local improvement initiatives.

A general pattern emerged rather quickly, namely that companies experienced the greatest difficulties in managing internal development initiatives in an area inbetween major strategic initiatives and local initiatives carried out solely in organizational units (sections and departments). The explanation offered goes as follows: The large company-wide effort usually attracts sufficient top management attention, and initiatives originating in one department usually are well managed by department and section heads.

In addition to characterize development initiatives according to their width in terms of the number of departments involved, they may also be characterized according to the depth of the change implied, spanning from large turn-around programs, strategic business developments, to continuous improvement tasks and cost reduction efforts. 
Although some of the lean techniques appear easy to understand, the implementation of their derived results implies a drastic change in the way of thinking and behavior on part of both operators and management.

\section{The Myriad of Development Activities}

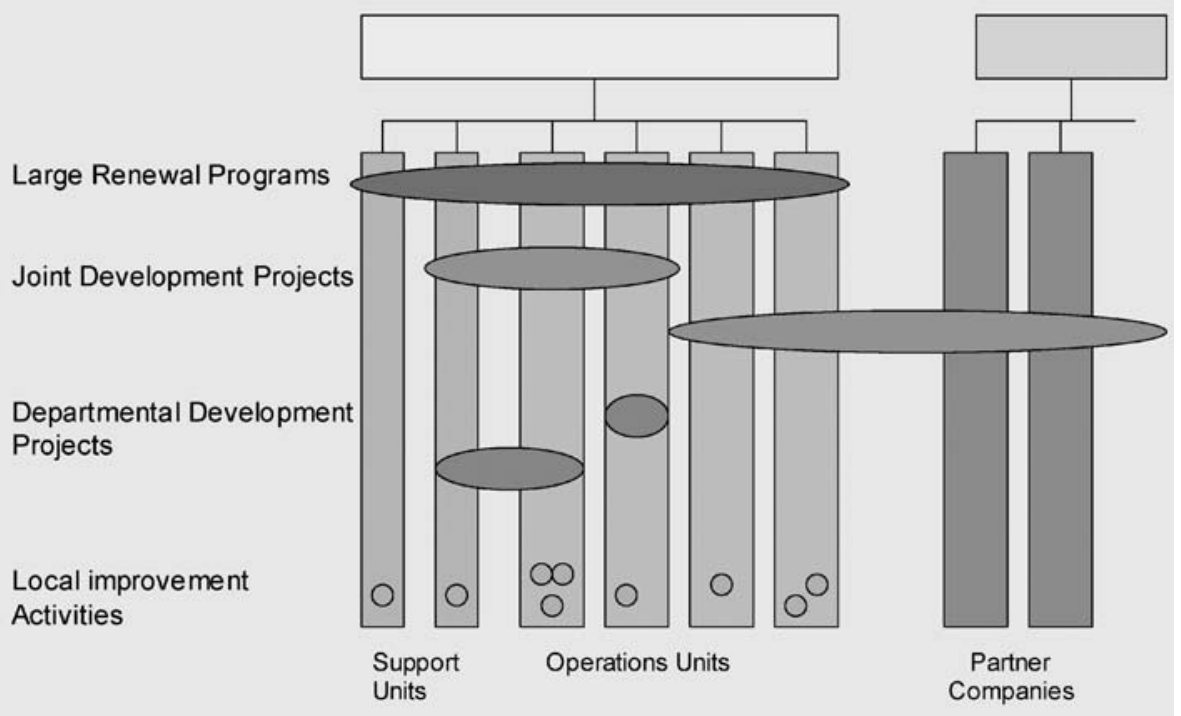

Fig. 1. The myriad of development activities

\section{Orchestration}

The empirical studies point to the increased turbulent environment that companies experience, indicating that the environment significantly determines the appropriate actions for management. Not only does a company experience short-term dynamics; but its strategic situation may also change over time, and consequently this calls for a regular shift in management focus. In periods, unforeseeable changes in the environment call for a capability to rapidly adjust implementation plans.

To acknowledge this complex and dynamic management situation we shall introduce the notion of orchestration to indicate that management of development initiatives is about harmonizing the activities of many interested parties into a concerted effort being able to continuously shifting the balance between actors and focal areas. The metaphor of managing the development of a company like conducting an orchestra or a band may capture important characteristics. For example to create a uniform mode of expression from different instruments; to let the theme shift from one group of instruments to another; to allow for individual interpretation and sometimes improvisation, yet maintaining the overall theme and mood of the piece; to 
change the tempo and expressions during the piece; and to create an impression of a whole through a sequence of movements.

Implementing lean thinking requires a concerted effort to initiate and realize a broad organizational development process. Not only is it necessary to coordinate the various activities directly associated with implementation of lean. But in view of the myriad of development initiatives in progress at any point in time such an effort cannot be planned as a stand-alone endeavor but should be viewed in relation to all development activities in progress in the company. For example, some initiatives well under way may support a lean effort, if slightly adjusted; other improvement initiatives may be in direct conflict with a lean effort and should be stopped. Thus, it is important to realize that a lean program necessarily has to tie in to the other development efforts undertaken; they are all competing for management attention and organizational capacity.

\subsection{Interdependencies among improvement initiatives}

Because many development activities have been initiated by different persons and functions, a major challenge to the management of a myriad of development initiatives is to identify ways in which they are interrelated and thereafter to seek to make use of this interdependency by creating an appropriate degree of synergy, for example by coordinating selected activities across functional and departmental lines. In addition to the traditional network of activities based on precedence relationships, there are several kinds of interdependencies.

\section{Time horizon}

The proposed development activities, as well as activities already in progress, may be characterized according to the built-in time horizon.

- Short-term activities (0-2 years), for example a productivity increase project, a market penetration effort, or a quality improvement program

- Medium-term activities (2-5 years); for example development of a new product and corresponding production system, introduction of new manufacturing process technology

- Long-term activities (beyond 5 years); for example exploration of new business opportunities, implementing a global manufacturing strategy

Different criteria and performance measures apply to each time horizon, and it is very difficult, if meaningful at all, to project initiatives on to the same scale. However, a table indicating all development and improvement activities may inspire management to realize if there is a proper balance, and if short-term activities can be related to long-term activities, and vice versa.

\section{Interdependencies across disciplines and functions}

A large development effort, such as lean implementation, requires a contribution from several disciplines and functions. If these areas are viewed as parallel streams of activities, it is possible to identify interdependencies. For example, production engineering may make it possible to reduce the batch size drastically; organizing in production groups may provide a basis for decentralized planning, etc. 


\section{Business processes}

In recent years, process thinking has brought new perspectives to the study of operations management. Key business processes as well as supporting processes are identified. Moreover, in several companies two or more parallel business processes have been identified, each pertaining to a specific product group or group of customers. Such a picture may support identification of needs for improvements as well as establishment of a coherent program for a concerted effort.

\subsection{Forming and managing interrelated development activities}

The traditional portfolio management has been used in product development to ensure an appropriate mixture of mature and novel products [6]. Also in financial management the portfolio theory has been used to seek a combination of development projects [7]. Several methods have been developed especially with the use of Management Science techniques to select among competing proposed development projects a portfolio that maximizes the expected revenue within a given budget.

However, internal development activities do not necessarily have the same types of interdependencies as do product development projects. Furthermore, turbulent internal and external conditions require that a company should be able to adopt a broader approach in order to capture the many interdependencies among internal development initiatives and to manage their dynamic nature.

Two examples from the empirical studies illustrate ways of managing interdependencies:

(1) A software company needed to change its process of delivering software from a Big Bang roll-out plan to more frequent releases, because of constant changing conditions and demands in the environment. They applied a new rolling wave plan combined with time boxes, and adopted elements from the concept of the learning organization.

(2) Three small manufacturing companies from different industries have adopted measures concerning the ability to act quickly. Their primary agent is visible management, e.g. managers walking and talking around and weekly information to all employees about the latest customer contacts and market situation.

We propose that implementing lean through an orchestrated effort be carried out by first analyzing interdependencies among internal development initiatives pertaining to lean implementation. It would encompass new proposed initiatives as well as activities already in progress. Second, they should be formed (composed, shaped, scoped) into either a campaign or a program. We see a campaign as a short-term effort of coordinated decentralized initiatives, typically running for two years, guided by a vision and slogan. A program represents a broader, well-structured set of development projects addressing both short-term and long-term goals.

Third, the campaign or program should be implemented by adopting an organizational learning approach, allowing for experimentation and adjustments called for by external and internal changes. 
The case studies of Danish companies point to several means of orchestrating a campaign or a program adopting several ideas from the growing interest in agile project management [8].

\section{Develop a vision}

Many authors recommend that an overall vision be developed, e.g. [9], [1], [10]. Not only does a manufacturing vision serve as a link to corporate strategy, but it will motivate all persons involved in lean implementation by providing a shared, overall picture of where the company is heading, why, and with which results. Furthermore, a manufacturing vision will spur and focus creativity and will help explain: "What is in it for me?"

\section{Dispatch only a few development initiatives at a time}

The observed practice and thinking of management from the empirical studies showed that many managers deliberately overload the organization and initiate new development projects with no regard to the available capacity of the organization. Not only does this lead to stress in the organization and long through-put times for the projects, but management risks to loose overview of the large number of ongoing development initiatives.

Some companies were able to cut the number of development projects to one half, partly by discontinuing dying projects starving for management attention. In other companies a program was formed, but only a few development projects were selected, and furthermore only the first phases of these projects were actually dispatched. This allowed management to adjust the course within a short horizon and thus obtained a high degree of flexibility in view of the dynamic environment.

\section{Visualizing}

In a turbulent environment it is difficult to specify clearly the desired end-result. It is just like walking on the beach looking for a beautiful stone; first when you see a number of stones, it is possible to determine the beautiful ones. A way of coping with the many interdependencies among development initiatives is continuously to visualize the individual expected results as a basis for discussing how they eventually may contribute to the overall vision. Prototyping is such a means used in product development and software development. We propose that prototyping should be applied also for internal development.

\section{Adopt a Time-Box planning principle}

Traditional project planning is concerned with the time duration until a given activity is completed. In the face of the dynamic environment, software development managers have successfully adopted a Time-Box principle, characterized by frequent deliveries. At the end of the period, all parallel projects are discussed and coordinated. Typically, this leads to adjustments in direction and scope for the individual projects.

\section{The management behavior will change}

Adopting a more agile approach to orchestrate internal development initiatives will imply a change in the management behavior towards conceptual planning, coaching through interacting, and discussing issues, rather than detailed program and project planning. 


\section{Behavioral aspects}

According to recent experiences of several Danish companies engaged in implementing lean the greatest challenge to ensure a successful implementation and realization of its potential lies in managing organizational changes. Following an organizational learning approach these experiences may be formulated into a set of recommendations:

\section{Enable people to identify value for customers}

To deliver value is the primary principle in lean thinking. Understanding the situation of the customers and end-users guides the assessment of which activities have value.

\section{Enable people to identify waste}

It is not sufficient to talk about reducing waste; each person should be told how to identify waste. For example, a short training course on the shop floor with built-in exercises enabled operators to see many different types of waste; and they started to propose ways of reducing waste.

\section{Enable people to see a business process}

Often the ERP system prescribes an in-process inventory inserted between two subsequent processes. In consequence operators miss the opportunity to get to know who is the sender and who is the receiver of goods and information in a business process. In one company, for spare parts produced in high volume managers chose to eliminate all in-process inventory along the production process; they even painted the boxes red and told the operators to contact the sender and receiver to discuss daily planning problems - with the result that the through-put time was reduced to one fourth.

\section{Hasten slowly}

Often, management is eager to rapidly implement planned changes in order to realize the identified potential benefit. Yet, the organizational changes are significant, for example new working habits, skills and attitudes have to be developed. This is more likely to be successful, if done at a pace in which the operators do not feel forced to adopt new qualifications and working modes. Therefore, a preparation phase should be inserted during which operators are trained and motivated, for example by use of games, exercises and simulations.

An organizational learning approach will favour making experiments. Among other things this will allow for anchoring the intended change, will create ownership and will lead to innovative proposed solutions from operators and middle management. This will also stimulate a continuous effort beyond a program or campaign to strive for lean. 


\section{Summary}

The empirical studies of more than 30 Danish companies have suggested that an an point in time there are many internal development initiatives in progress. Therefore, implementation of lean, encompassing itself a blend of different development activities, will need to be tied in with ongoing initiatives and new proposals competing with for management attention and funding.

The complex environment and operations of modern companies call for means for developing a coherent picture of internal development activities. It was argued that being able to address the interdependencies among such activities is key to successful company development. A new approach was introduced, called orchestration, using the metaphor from conducting an orchestra or a band. Identifying and working with the interdependencies among the individual internal development activity was shown to form the basis for orchestration. Several dimensions of such interdependencies were offered.

Implementing lean through an orchestrated effort could be carried out as a program or a campaign, indicating that a concerted effort should be organized for a 2-3 year period. However, experience from the Danish companies indicated that the program should be planned and managed as an organizational learning process allowing for experimentation and adjustments called for by external and internal changes. Several means for orchestration were discussed. Also behavioral issues were identified and discussed.

The paper has pointed to a new direction for managing a multitude of simultaneous development activities in a complex and dynamic environment by introducing and exploring the notion of orchestration, suggesting agile project management methods be used for lean implementation.

\section{References}

1. Womack, J. P., and Jones, D. T. (1996) Lean Thinking, USA-Simon \& Schuster.

2. Voss, C. A. (1988) Success and failure in advanced manufacturing technology, International Journal of Technology Management, No. 3.

3. Kaplan, Robert S. \& Norton, David P. (2001) The Strategy-Focused Organization, Harvard Business School Press.

4. Mikkelsen, Hans (2005) Managing the myriad of projects (in Danish), Børsens Forlag.

5. Andersen, J.R., Riis, J.O. \& Mikkelsen, H. (2005) Agile Project Portfolio Management - A contribution to Company Development Competence, Proceedings of the ICAM 2005 International Conference on Agile Manufacturing, Helsinki, Finland. 
6. Cooper, R.G. (2005) Lean, Rapid, and Profitable New Product Development, Product Development Institute.

7. Sharpe, William F. (2000) Portfolio theory and capital markets, McGraw-Hill, New York.

8. Highsmith, Jim (2004) Agile Project Management, Addison-Wesley.

9. Kotter, John P (1996) Leading Change, Harvard Business School Press.

10. Riis, Jens O \& Johansen, John (2003) Developing a manufacturing vision, International Journal of Production Planning \& Control, Vol. 14, No. 4. 